\title{
HACIA UN FUTURO MEJOR: \\ EDUCACIÓN Y FORMACIÓN PARA EL DESARROLLO ECONÓMICO DE SINGAPUR DESDE 1965 DE LEE SING KONG, GOH CHOR BOON, BIRGER FREDRIKSEN Y TAN JEE PENG*
}

\section{Patricio Felmer Aichele}

Este libro trata de Singapur, pequeña y joven nación asiática que ha recorrido un singular camino hacia el desarrollo económico, marcado por la carencia de recursos naturales y por su apuesta por la educación. Escrito por protagonistas de esta historia, el libro ofrece muchas lecturas; aquí se encuentran desde las pequeñas recetas hasta los grandes sueños.

Muchos pensarán que la historia de Singapur es interesante, pero que no tiene nada que ver con nosotros y por tanto su estudio es solo un ejercicio intelectual. Otros dirán que poco se puede sacar de aquí, pues la realidad de Singapur es tan distinta a la nuestra. También habrá quienes piensen que sus logros se deben a su ancestral cultura china, por lo tanto imposibles de alcanzar para nosotros. Y habrá quienes descalifiquen a Singapur por su sistema político, apelando unos a su extremo capitalismo y otros a su centralismo estatista. Por último habrá quienes piensen que Singapur está muy lejos. Pero es precisamente la diferencia, el contraste y la lejanía con nuestra realidad lo que hace atractiva la experiencia de Singapur. Esto nos permite pensar, razonar y aprender. Es lo singular, lo irrepetible de Singapur lo que nos atrae y abre nuestro interés. Este libro se presenta con una riqueza infinita de ideas que despiertan una y otra vez nuestra inquietud y curiosidad, y su lectura enriquecerá nuestro debate sobre la educación que queremos para Chile.

En el prólogo de la edición original, el ministro de Economía y de Educación de Singapur dice: "Los académicos, los responsables de las políticas del área de educación y los profesores pueden rescatar enseñanzas útiles de la experiencia de Singapur, tal como Singapur rescata y evalúa de manera constante las ideas y enseñanzas de otras partes del mundo". Esta afirmación, mucho más que la opinión de un ministro, representa un elemento cultural que impresiona a todo quien observa de cerca la práctica educacional de Singapur. Mirar permanentemente lo que sucede, lo que se estudia y lo que se hace en otras realidades, con el fin de incorporarlo a su propio quehacer, es una práctica que sorprende y que parece entrar en contradicción con un principio básico, arraigado también en todos los ámbitos de la educación en Singapur: "La educación es una actividad humana extremadamente contextualizada". Es tal vez la justa comprensión de lo

* Lee, S.K., Goh, C. B., Fredriksen, B., y Tan, J. P., Hacia un futuro mejor: educación y formación para el desarrollo económico de Singapur desde 1965 (Toward a Better Future: Education and Training for Economic Development in Singapore since 1965, World Bank, 2008). La edición en español fue editada por la Academia Chilena de Ciencias, 2012. 
que hacen los demás junto a la conciencia de la imposibilidad de trasladar con éxito un experiencia educacional fuera de su contexto; es esta síntesis quizás lo más importante que podemos aprender de Singapur.

Singapur nace como país independiente en agosto de 1965, cuando el Parlamento de Malasia literalmente expulsó a esta pequeña isla de su federación. Nace sin recursos naturales, con casi la mitad de su población analfabeta, disgregada racialmente y hablando al menos cuatro lenguas distintas: inglés, chino mandarín, tamil y malayo. En esta realidad poco alentadora, las autoridades políticas debieron idear un plan para no perecer política y económicamente. Sin poder recurrir a la explotación de recursos naturales para desarrollar la economía, buscaron asociación con empresas extranjeras para que se instalaran en Singapur y desarrollaran la industria de manufactura, aprovechando la mano de obra barata. Paralelamente decidieron desarrollar un recurso que sí tenían y con un potencial inimaginable: la inteligencia y capacidad creadora en cada uno de sus habitantes. Y para cultivarlas, desde el primer día invirtieron fuertemente, de manera sostenida y creciente en educación. Uno puede imaginar qué otras tantas prioridades y urgencias había que atender para el desarrollo económico. Sin embargo, priorizaron los recursos para la educación, concibiéndola como una inversión permanente que crea la base del desarrollo buscado.

Singapur invirtió en infraestructura construyendo escuelas en forma masiva y contratando profesores, muchos de ellos todavía estudiantes. En un continuo ajuste y coordinación entre el ministerio de Educación, la Universidad formadora de docentes y las escuelas, Singapur fue elevando la calidad del currículo nacional, de los textos, de las escuelas y sus directores, de la formación inicial y continua de los profesores. Fue fortaleciendo los equipos técnicos del ministerio de Educación y los grupos académicos de la Universidad, buscando en el extranjero los conocimientos que no poseía. Creó una carrera docente que se inicia cuando un estudiante es seleccionado para formarse como profesor y que al egreso ofrece un sueldo igual al de ingenieros del servicio público. Y todo este desarrollo educacional para que cada uno de los niños y niñas de Singapur, sin ninguna distinción y en forma gratuita, reciban cada vez una mejor educación.

La experiencia de Singapur relatada en este libro nos muestra en forma nítida y clara que no es cierto que haya que esperar el desarrollo económico para tener una educación de calidad para todos, como a veces se nos hace creer, sino que, por el contrario, hay que invertir en educación para lograr el desarrollo económico, asignando los recursos necesarios para que la educación no sea un freno que lo retrase, sino un motor que lo acelere.

Si Singapur, siendo una nación pobre y sin recursos naturales, pudo invertir los recursos necesarios para lograr una educación de calidad para todos, ¿por qué nosotros nos farreamos el futuro, teniendo enormes recursos naturales y partiendo de un piso muy superior? No cabe duda que nosotros podríamos hacerlo mucho mejor y más rápido que Singapur. 